\title{
¿Penas sin humillaciones? \\ Límites al derecho penal derivados del respeto a la dignidad humana*
}

\author{
Fernando León Tamayo Arboleda" \\ Juan Oberto Sotomayor Acosta"*
}

Recibido: 26 de abril de 2016 • Aprobado: 22 de septiembre del 2017

https://doi.org/10.22395/ojum.v17n33a1

\begin{abstract}
RESUMEN
El presente texto se propone analizar los límites a la intervención penal derivados del contenido constitucional de la dignidad humana, entendida como intangibilidad de integridad física y moral del individuo, no sin antes precisar, de forma muy breve, la función del principio de respeto a la dignidad humana en el derecho penal, en general, y la manera como las diferentes atribuciones que caracterizan este principio según su elaboración por parte de la Corte Constitucional se configuran como límites al poder penal del Estado. Para ello, se realiza un análisis de la jurisprudencia de la Corte Constitucional usando herramientas de la dogmática constitucional y penal. El artículo propone que, a pesar de la diáspora jurisprudencial y la complejidad del concepto dignidad humana, es posible derivar un contenido del mismo que sirva como limitación del derecho penal en el marco del Estado de derecho.
\end{abstract}

Palabras clave: dignidad humana, derechos humanos, derecho penal, derecho constitucional.

Este artículo es producto del proyecto de investigación "Las garantías penales como límite y guía en la solución de problemas penales complejos: la necesidad de evitar atajos", dirigido por el profesor Miguel Díaz y García-Conlledo (Universidad de León, España), con financiación del Ministerio de Economía y Competitividad, código DER2013-47511-R, de España; y de la Universidad Eafit, código 621 - 000008, en Colombia.

** Abogado, Universidad de Antioquia, Medellín, Colombia. Especialista en Derecho Penal, Universidad Eafit, Medellín, Colombia. Magíster en Derecho Penal, Universidad Eafit, Medellín, Colombia. Candidato a doctor en Derecho,Universidad de Los Andes, Bogotá, Colombia. Asistente graduado de Docencia, Universidad de los Andes, Bogotá, Colombia. Cra 1 \#18a-12, Bloque RGC, Bogotá, Colombia. Correo electrónico: fernandoleontamayo@hotmail.com fl.tamayo10@uniandes.edu.co.https://orcid.org/0000-0003-0960-0849

... Abogado, Universidad de Medellín, Medellín, Colombia. Doctor en Derecho, Universidad de Salamanca, Salamanca, España. Profesor de Derecho Penal, Universidad Eafit, Medellín, Colombia. Carrera 49 \# 7sur-50, Bloque 27, Medellín, Colombia. Correo electrónico: j.sotoma@eafit.edu.co.https://orcid.org/0000-0001 8173$\underline{7562}$ 


\title{
Sentences without Humiliation? Limits to Criminal Law Arising from Respect for Human Dignity
}

\begin{abstract}
Th The purpose of this text is to analyze the limits to criminal intervention arising from the constitutional content of human dignity, understood as the inviolability of the physical and moral integrity of the individual, but not before specifying, in a very brief manner, the function of the principle of respect for human dignity in criminal law in general, and the way in which different powers that characterize this principle according to its elaboration by the Constitutional Court are configured as limits to the criminal power of the State. To this end, an analysis of the jurisprudence of the Constitutional Court is carried out using tools of constitutional and criminal dogma. The paper proposes that, in spite of the jurisprudential diaspora and the complexity of the concept of human dignity, it is possible to derive a content from it that serves as a limitation of criminal law within the framework of the Rule of Law.
\end{abstract}

Keywords: Human dignity; human rights; criminal law; constitutional law.

\section{Penas sem humilhações? Limites do direito penal derivados do respeito à dignidade humana}

\section{RESUMO}

O presente texto se propõe a analisar os limites da intervenção penal derivados do conteúdo constitucional da dignidade humana, entendida como intangibilidade de integridade física e moral do indivíduo, não sem antes determinar, de forma muito breve, a função do princípio de respeito à dignidade humana no direito penal, em geral, e a maneira como as diferentes atribuições que caracterizam esse princípio de acordo com sua elaboração por parte da Corte Constitucional se configuram como limites ao poder penal do Estado. Para isso, realiza-se uma análise da jurisprudência da Corte Constitucional usando ferramentas da dogmática constitucional e penal. O artigo propõe que, apesar da diáspora jurisprudencial e da complexidade do conceito de "dignidade humana", é possível derivar um conteúdo deste que sirva como limitação do direito penal no âmbito do Estado de direito.

Palavras-chave: Dignidade humana; direito constitucional; direito penal; direitos humanos. 


\section{INTRODUCCIÓN}

El artículo 1 de la Constitución Política establece que Colombia es un Estado social de Derecho fundado en el respeto a la dignidad humana. Por su parte, según la norma rectora recogida en el artículo 1 del C. P., "el derecho penal tendrá como fundamento el respeto a la dignidad humana".

Aunque suele ser lugar común apelar a la dignidad humana a la hora de interpretar el texto constitucional, y muy en particular las normas relativas a derechos fundamentales, lo cierto es que recurrir al mismo concepto para fundamentar el derecho penal genera más perplejidades que certezas y más de un interrogante por resolver, pues el derecho penal de hoy tiene más de máquina del terror y de distribución de indignidades que de mecanismo subsidiario de protección de bienes jurídicos. Así lo acredita la situación actual de las cárceles colombianas, en cuanto producto final de la aplicación del sistema penal, que a decir de la propia Corte Constitucional "se encuentra en un estado de cosas contrario al orden constitucional vigente de manera grosera, que conlleva un desconocimiento de la dignidad humana..., incompatible con un Estado social y democrático de derecho" (Corte Constitucional, 2013) '.

De ahí que los citados textos legales planteen un reto hermenéutico importante, toda vez que, si se quiere trascender el simple uso retórico de la dignidad huma-

\footnotetext{
Al respecto puede consultarse, además: Corte Constitucional (1993) y (2015b).
}

na, es necesario avanzar más allá de las meras declaraciones formales y delimitar un contenido específico de aquello que en estos momentos significa, desde el punto de vista constitucional (al menos mientras la interpretación se pretenda en el ámbito de la legitimación interna), un trato acorde con la dignidad humana. Y es así por cuanto se está ante un concepto indeterminado, cuyo contenido solo es posible aprehender a partir de atribuciones de significado previas, por lo que en realidad toda elaboración jurídica sobre la dignidad humana comienza en el ámbito de la política y no en el legal (Sotomayor Acosta \& Tamayo Arboleda, 2017).

Pese a estas dificultades conceptuales y en medio de sus profusos pronunciamientos sobre el tema, la Corte Constitucional ha ido consolidando una línea jurisprudencial sobre la delimitación del contenido específico del respeto a la dignidad humana como principio constitucional autónomo, que se puede resumir en la exigencia de una serie de atribuciones específicas, recogidas de manera sintética en la sentencia T-881 de 2002 (Corte Constitucional, 2002e) ${ }^{2}$ :

a. El respeto a la dignidad humana entendida como autonomía individual, esto es, como posibilidad de diseñar un plan vital, y de determinarse según sus características ("vivir como quiera").

b. La intangibilidad de los bienes no patrimoniales, de la integridad moral y física ("vivir sin humillaciones").

En la doctrina, por todos, (Quinche Ramírez, 2012) 
c. La prestación de ciertas condiciones materiales concretas de existencia ("vivir bien").

Esta caracterización general ha centrado el concepto de dignidad humana en la atribución de lo digno, dejando, quizá, en un segundo plano la referencia a lo humano, cualidad que permite enriquecer el contenido del principio con dos exigencias podría decirse que ontológicas previas, las cuales se encuentran implícitas en la elaboración jurisprudencial: el reconocimiento de las limitaciones del actuar humano, por una parte, y la no diferenciación entre los individuos de la especie humana, por otra.

A partir de este contenido específico podría decirse que la dignidad humana, en cuanto fundamento del modelo de Estado constitucionalmente asumido, cumple un doble papel: por una parte, sirve de límite a las posibilidades de actuación del Estado, como libertad negativa (Berlin, 2003; Ferrajoli, 1995) que impide la intervención estatal en ámbitos no dominables por los individuos de la especie humana o reservados de manera exclusiva a su esfera individual. Por otra, la dignidad humana cumple también un papel como libertad positiva o de prestación (Berlin, 2003; Ferrajoli 2011b), en lo atinente a la optimización de las condiciones de vida. Al primer grupo pertenece el reconocimiento de las limitaciones del actuar humano y de la igualdad entre individuos, la no interferencia en la libre autodeterminación del sujeto y la intangibilidad de las esferas física y moral. La función prestacional la recoge, por su parte, la exigencia de condiciones materiales para vivir bien.

El presente texto se propone analizar los límites a la intervención penal derivados del contenido constitucional de la dignidad humana entendida como intangibilidad de integridad física y moral del individuo, no sin antes precisar, de forma muy breve, la función del principio de respeto a la dignidad humana en el derecho penal, en general, y la manera como las diferentes atribuciones que caracterizan este principio -según su elaboración por parte de la Corte Constitucional- se configuran como límites al poder penal del Estado.

Para la realización de lo anterior, se hizo inicialmente una búsqueda de toda la jurisprudencia de la Corte Suprema de Justicia referida a la dignidad humana en materia penal. En el paso siguiente se establecieron líneas de argumentación de la Corte Constitucional en torno al contenido de la dignidad humana, prestando especial atención a aquellos eventos en los cuales el máximo órgano constitucional establecía la dignidad humana como límite al ius piniendi del Estado; y desechando aquellas sentencias en los cuales la dignidad humana aparecía como un recurso meramente retórico. Finalmente, se realizó un análisis crítico de la posición de la Corte a partir de herramientas de la dogmática constitucional y penal que derivaron en la construcción de los contenidos presentados en el texto.

Para dar cuenta de los hallazgos de la investigación, el presente artículo se divide 
en tres partes. En la primera de ellas, se expone teóricamente la discusión en torno a la dignidad humana en el contexto del derecho penal, con especial atención a la complejidad que conlleva discutir el contenido de la dignidad humana en un sistema soportado en una forma de castigo (la cárcel) que es opuesta a la idea misma de dignidad humana. La segunda parte del texto se concentra en el análisis de la jurisprudencia de la Corte Constitucional, para describir en detalle el contenido de la dignidad humana y las implicaciones derivadas del mismo en cuanto a la limitación del poder punitivo. Finalmente, se presentan las conclusiones del texto.

\section{EL DIFÍCIL ENCUENTRO DE LA DIGNIDAD HUMANA CON EL DERECHO PENAL}

Si las atribuciones del respeto a la dignidad humana se predican con un carácter general, que para el Estado son obligaciones negativas y positivas, es lógico pensar que las funciones restrictivas de este principio se tornen aún más relevantes y exigentes cuando se trata de enfrentar la cara más cruel y con frecuencia despiadada de la actividad estatal, cual es la punitiva. Y precisamente por ello, lo primero que salta a la vista es la contradicción que supone la exigencia constitucional de pro tección de la dignidad humana, por una parte, y la utilización por parte del Estado de los instrumentos penales, por otra.

En esta dirección, parece bastante evidente que el mantenimiento de ciertas condiciones materiales concretas de existencia, inherente a la garantía de respeto a la dignidad humana, es incompatible con los medios penales, toda vez que la pena en estricto sentido no es un medio para vivir bien, pues al tiempo que en abstracto podría generar algún bienestar a la mayoría, perjudica en concreto al penado. En rigor, hacer sufrir (que es en lo que consiste la pena) no puede ser visto como un derecho sino como un poder (Prieto Sanchís, 2011; Zaffaroni, Alagia E Slokar, 2002; Sotomayor Acosta, 1999); luego, no existe un derecho a castigar y mucho menos un deber constitucional en tal sentido. Si se requiere que el Estado intervenga para mejorar las condiciones materiales de existencia acorde con las exigencias de una vida digna, lo procedente no es crear un delito sino la realización de una acción fáctica positiva (Arango, 2005) y, en últimas, la implementación de una política social adecuada, intervención que en el Estado constitucional se encuentra garantizada a través de las normas que protegen los derechos sociales (Ferrajoli, 2011b). Por el contrario, las garantías penales son garantías negativas (Ferrajoli, 2011a) consistentes en prohibiciones orientadas a la tutela de los derechos de libertad que en relación con el contenido del respeto a la dignidad humana implica el reconocimiento de los límites del actuar humano, la exigencia de igualdad entre humanos, el respeto a la autonomía individual y la intangibilidad de la integridad física y moral. Estas limitaciones operan con carácter general y por tanto también y con mayor razón, frente al poder penal del Estado.

Luego, cuando el artículo 1 C. P. prescribe que el derecho penal tendrá como 
fundamento el respeto a la dignidad humana, no puede significar que la razón para penar es el respeto a la dignidad humana; lo que debe interpretarse, más bien, es que el derecho penal encuentra su razón de ser en la limitación de la intervención punitiva estatal, para evitar que en el ejercicio de dicha actividad se desconozcan las exigencias de un trato humano y digno conforme al modelo constitucional (Sotomayor Acosta \& Tamayo Arboleda, 2017).

\section{a. La dignidad humana como reconocimiento de los límites del actuar humano}

Aunque la Corte Constitucional no ha desarrollado específicamente este aspecto, toda su construcción del concepto de dignidad humana tiene como punto de partida un ser humano inserto en un mundo físico y una realidad social que lo condiciona, y que el individuo no siempre está en capacidad de superar y, por ende, no se le puede exigir que lo haga. Es precisamente esta referencia a lo humano la que conduce a lo que genéricamente podría denominarse principio de responsabilidad como presupuesto ineludible de cualquier poder sancionador y que en el campo del derecho penal se reconoce como principio de culpabilidad, el cual, entendido en sentido amplio ${ }^{3}$, se concreta en una serie de garantías que limitan la responsabilidad penal solo a los actos que el ser humano está en capacidad y le es exigible evitar,

\footnotetext{
Sobre este sentido amplio del principio de culpabilidad y las garantías que le son inherentes, véase a Borja Jiménez (1992), Mir Puig (2008), Luzón Peña (2012). En Colombia, Fernández Carrasquilla (2011), Velásquez (2009) y Sotomayor Acosta (1996)
}

lo que en el campo penal conlleva la exigencia siempre de responsabilidad personal y subjetiva, y las consiguientes prohibiciones de la responsabilidad colectiva (o por hechos ajenos) y objetiva (Sotomayor Acosta \& Tamayo Arboleda, 2017).

\section{b. La dignidad humana como exigencia de igualdad}

El tratamiento de un individuo como humano y digno depende solo de su pertenencia a la especie humana, lo que hace de la igualdad, a pesar de estar consagrada en una disposición constitucional diferente (artículo 13 Const. Pol.), una consecuencia obligada del concepto de dignidad humana, pues todo lo humano ${ }^{4}$, independiente de la raza, religión, preferencia sexual, opción de vida, etc., es siempre acreedor de esta dignidad (Corte Constitucional, 2015d; Corte Constitucional, 2003a; Fernández Carrasquilla, 2011; Sotomayor Acosta, 1996). Se concreta en el derecho a recibir un trato igualitario de las autoridades, en dos sentidos: por una parte, en la protección de los derechos frente a las injerencias de otras personas (igualdad de protección) y, por otra, en las garantías frente las pretensiones punitivas del propio Estado. Ahora bien, el reconocimiento de que ciertas personas se encuentran en situación material de

\footnotetext{
En este caso se hace referencia a un concepto puramente biológico de especie humana, por entender que la sola pertenencia a dicha especie es suficiente para ser acreedor de la atribución de la dignidad humana. En todo caso, ello no implica desconocer que lo humano que ocupa al derecho es una construcción cultural.
} 
desventaja frente a las exigencias sociales ha conducido a la exigencia de diferenciación como contenido adicional del principio de igualdad 5 , por lo que junto al deber negativo de no discriminación el Estado tiene también el deber positivo de intervenir en favor de las personas o grupos en situación de desigualdad. En el campo penal ello puede conducir a una protección especial de los derechos de individuos en situación de desigualdad material, por una parte, y a unas mayores garantías o unas mayores barreras de contención frente a las pretensiones punitivas del Estado, cuando se trata de juzgar a quien se encuentra en una situación material de desventaja, por otra (Sotomayor Acosta \& Tamayo Arboleda, 2017).

\section{c. La dignidad humana entendida como autonomía o como posibilidad de diseñar un plan vital y de determinarse según sus características (vivir como quiera) (Sotomayor Acosta \& Tamayo Arboleda, 2017)}

La dignidad como ejercicio de la autonomía personal ha sido entendida por la Corte Constitucional como la posibilidad de cada quien a decidir sobre su proyecto de vida. Ello se ha traducido en protecciones concretas, algunas de las cuales están constitucionalizadas de forma independiente y otras han sido integradas por la jurisprudencia constitucional al núcleo esencial de la dignidad humana.

Cfr. Cepeda (1992), Bernal Pulido (2005), Rodríguez Garavito (2007), Quinche Ramírez (2012). Sobre este contenido del derecho a la igualdad se ha mantenido una clara línea en la jurisprudencia de la Corte Constitucional (1993d, 1996a, 1999, 2001b).
Así, bajo la autonomía personal suelen agruparse los derechos constitucionales a la libertad de expresión, la libertad de culto, la posibilidad de decidir libremente sobre el estilo de vida, la decisión sobre las preferencias sexuales y otras libertades similares ${ }^{6}$.

En materia penal ello significa que al ciudadano no puede perseguírsele penalmente por la forma en que ha decidido llevar su vida, máxime cuando esta autodeterminación no perjudica o beneficia a nadie diferente al propio sujeto. Tomarse en serio la posibilidad del individuo de auto-determinarse implica, en síntesis, que el derecho penal solo pueda concebirse como derecho penal de acto, nunca como derecho penal de autor (Zaffaroni, Alagia E Slokar, 2002).

La exigencia de un derecho penal de acto tiene dos dimensiones: por una parte, garantiza la indemnidad del fuero interno del sujeto, en virtud del amparo de la libertad de conciencia y de pensamiento y la consiguiente libertad de expresión. En segundo lugar, supone también la protección de la libertad del individuo para desarrollar el modo de vida conforme a sus propios ideales y en definitiva a vivir como quiera. Luego, nadie debería ser penalizado por defender unas determinadas ideas o valores, por irracionales que fuesen, ni tampoco por adoptar un modo de vida determinado, por inmoral o incómodo que pueda ser considerado; lo

\footnotetext{
En especial, Corte Constitucional (2002e). La fundamentación moral de este principio puede consultarse en Nino (1989).
} 
primero conduciría a un derecho penal del ánimo o la actitud interna y el segundo a un derecho penal basado en la peligrosidad o el carácter. De ahí la inadmisibilidad de a) la peligrosidad como fundamento de cualquier sanción penal (Sotomayor Acosta, 1996); b) los delitos de opinión, como es el caso del delito de apología del genocidio (artículo 102 C.P.); c) las protecciones paternalistas, en las que el Estado asume una posición de defensa del individuo frente a sí mismo (Roxin, 2007; von Hirsch, 2007; Gallego García, 2005); d) las agravantes fundadas de manera exclusiva en los móviles del autor, pues en tal caso el sujeto, para no incurrir en la agravante, tendría que cambiar su manera de pensar o su sistema de valores.

\section{d. La dignidad humana entendida como intangibilidad de los bienes no patrimoniales, integridad física e integridad moral (vivir sin humillaciones)}

En este caso se alude a la prohibición de interferencias en las esferas física y moral del individuo, en tanto presupuestos para la realización de su propio proyecto de vida (Nino, 1989). La jurisprudencia de la Corte Constitucional ha entendido que el respeto a la dignidad humana implica la intangibilidad tanto de la esfera física como moral del individuo, esto es, el derecho a "vivir sin humillaciones", exigencia que, entre todas las atribuciones de la dignidad humana, se presenta sin duda como la más problemática para el derecho penal, toda vez que toca directamente con el contenido de las penas. De ahí entonces la necesidad de precisar los límites que desde este punto de vista la Constitución impone al derecho penal.

\section{LOS LIMITES A LA INTERVENCIÓN PENAL DERIVADOS DE LA DIGNIDAD HUMANA ENTENDIDA COMO INTANGIBILIDAD DE LOS BIENES NO PATRIMONIALES, INTEGRIDAD FÍSICA E INTEGRIDAD MORAL (VIVIR SIN HUMILLACIONES)}

La delimitación de las garantías derivadas de la intangibilidad de los bienes de la esfera física y moral del individuo es particularmente problemática en el campo del derecho penal, dado que la pena por su propia naturaleza es un acto al que se recurre (como fin o como medio) para, de manera intencional, generar sufrimiento en sus destinatarios (Nino, 1980), lo cual parecería difícilmente compatible con la existencia de un derecho a vivir sin humillaciones. Es por eso que en el Estado constitucional la pena solo es aceptable como mecanismo subsidiario, en un doble sentido: desde una perspectiva externa, en cuanto medida extrema a tener en cuenta solo cuando no sea posible una protección de los bienes jurídicos por medios menos drásticos que los penales, lo cual sugiere la búsqueda permanente de alternativas al derecho penal. Y, desde un punto de vista interno, la subsidiariedad obliga a evitar las medidas penales más graves, cuando el mismo efecto se pueda alcanzar por otros medios penales menos drásticos, lo que plantea la exigencia de penas alternativas (Lopera Mesa, 2006).

Pero aun cuando, en contra de las evidencias actuales, se aplicara solo de manera excepcional y subsidiaria, y los medios penales utilizados fuesen los menos aflictivos, la pena seguiría siendo lo que es, es 
decir, un mal, y por ende, el único deber constitucional existente en materia penal es el de restricción del uso de la pena: bien por la vía de la inadmisibilidad de algunas penas consideradas inhumanas o particularmente crueles o indignas o, bien, por la de la restricción de aquellas que resulten aceptables.

\section{a. La prohibición general de la tortura, y los tratos y penas crueles, inhumanos y degradantes (artículo 12 Const. Pol.)}

Se podría afirmar que para el derecho penal el respeto a la dignidad humana en el sentido de vivir sin humillaciones se concreta en la fórmula general de la prohibición de la tortura y los tratos y penas crueles, inhumanos y degradantes (artículo 12 Const. Pol.). Pero dadas las dificultades de determinación de lo "cruel", "inhumano" y "degradante" 7 , en principio parecería -al menos en el caso de las penas- que ha quedado en manos del legislador valorar lo que debe considerarse tal, por lo que su poder de configuración en esta materia solo se vería limitado por el amplio filtro de la prohibición de exceso (Corte Constitucional, 1993e; Corte Constitucional, 2002d). Debe tenerse presente, además, que conforme al artículo 1 de la Ley 70 de 1986, aprobatoria de la Convención contra la tortura y otros tratos o penas crueles, inhumanos o degradantes,

7 De hecho, son muy escasos los pronunciamientos jurisprudenciales en concreto sobre este tema, al cual parece acudirse en el control constitucional más como argumento retórico, para respaldar decisiones en las que el problema ha sido resuelto de manera previa acudiendo a otras reglas o principios. Al respecto, Corte Constitucional (2003a, 2003b).
"No se considerarán torturas los dolores o sufrimientos que sean consecuencia únicamente de sanciones legítimas, o que sean inherentes o incidentales a estas"; ello, salvo los casos extremos, hace difícil el cuestionamiento por este motivo de alguna clase de pena en abstracto.

Por eso ha sido el propio constituyente el que ha decidido restringir el poder del legislador, al consagrar de manera expresa en la Constitución algunas prohibiciones con carácter absoluto, como sucede con la pena de muerte, el destierro, la confiscación y la prisión perpetua.

El caso de la prisión merece una consideración aparte, pues las únicas limitaciones que en principio expresa el texto constitucional son las referidas a la prisión perpetua y por deudas (artículo 28 Const. Pol.), lo que parecería indicar su admisibilidad constitucional en las demás modalidades y eventos, pese a sus comprobados efectos devastadores en el ser humano. La cárcel, explica Ferrajoli,

\section{[...] ha sido siempre, en oposición a su modelo teórico y normativo, mucho más que la 'privación de un tiempo abstracto de libertad'. Inevi- tablemente ha conservado muchos elementos de aflicción física, que se manifiestan en las formas de vida y de tratamiento, y que difieren de las antiguas penas corporales solo porque no están concentradas en el tiempo, sino que se dilatan a lo largo de la duración de la pena (Ferrajoli, 1995: 412) (Cursiva textual).}

Por tal motivo, aun cuando la prisión como pena (no perpetua ni por deudas) 
pueda en abstracto considerarse constitucionalmente permitida, pese al alto grado de aflicción que conlleva, podría de todas maneras en un caso concreto configurar un trato cruel, inhumano o degradante, si las condiciones de su cumplimiento efectivo no satisfacen las exigencias mínimas de respeto a los derechos fundamentales de las personas privadas de la libertad. Como lo ha hecho constar el magistrado Palacio,

\section{[...] los únicos dolores y sufri- mientos que podrían estar justifi- cados en el ordenamiento jurídico en un Estado social de derecho y una sociedad democrática, son los que provienen de sanciones que tengan una correspondencia con los estándares internaciona- les de DDHH, especialmente de las leyes que se dirigen a la pro- tección de los individuos privados de su libertad (Corte Constitucio- nal, 2015a).}

El incumplimiento de tales exigencias es lo que ha llevado a la Corte Constitucional, en reiterada jurisprudencia, a declarar a las cárceles colombianas como un estado de cosas inconstitucional. Por ejemplo, en Corte Constitucional (1998), dijo la Corte:

Las cárceles colombianas se caracterizan por el hacinamiento, las graves deficiencias en materia de servicios públicos y asistenciales, el imperio de la violencia, la extorsión y la corrupción, y la carencia de oportunidades y medios para la resocialización de los reclusos. Esta situación se ajusta plenamente a la definición del estado de cosas inconstitucional. Y de allí se deduce una flagrante violación de un abanico de derechos fundamentales de los internos en los centros penitenciarios colombianos, tales como la dignidad, la vida e integridad personal, los derechos a la familia, a la salud, al trabajo y a la presunción de inocencia, etc.

Quince años después, (2013), la Corte Constitucional, entre otros aspectos, ratifica que:

[...] (i) los derechos constitucionales de las personas privadas de la libertad son violados de manera masiva y generalizada; (ii) las obligaciones de respeto, protección y garantía, derivadas de tales derechos, han sido incumplidas de forma prolongada; (iii) el Sistema ha institucionalizado prácticas claramente inconstitucionales, dentro de su funcionamiento cotidiano; (iv) hay una ausencia notoria de medidas legislativas, administrativas y presupuestales que se requieren con urgencia.

Luego, no cualquier privación de la libertad es aceptable como trato acorde con la exigencia constitucional de respeto a la dignidad humana.

Tampoco parece válido desde el punto de vista constitucional el incremento exorbitante de la duración de la pena de prisión o el recurso desmesurado a la prisión (en particular a la prisión preventiva), con el objetivo de presionar lo suficiente al imputado para que acepte su responsabilidad o llegue a un acuerdo con la Fiscalía, 
a cambio de una rebaja de la pena, como ha sucedido en Colombia, entre otras, con las leyes 890 de 1994 y 1242 de 2007, la primera de las cuales ordenó para todos los delitos un incremento de la pena mínima en una tercera parte y del máximo en la mitad, argumentando la necesidad de unas penas lo suficientemente altas para un "buen funcionamiento" del sistema acusatorio, como se reconoce en la propia exposición de motivos, en la cual se afirma que

La razón que sustenta tales incrementos está ligada con la adopción de un sistema de rebaja de penas (materia regulada en el Código de Procedimiento Penal) que surge como resultado de la implementación de mecanismos de 'colaboración' con la justicia que permitan el desarrollo eficaz de las investigaciones en contra de grupos de delincuencia organizada y, al mismo tiempo, aseguren la imposición de sanciones proporcionales a la naturaleza de los delitos que se castigan.

A tal efecto, se ha producido en Colombia un incremento desmesurado de las penas con el objetivo principal de constreñir al imputado a que renuncie al juicio y acepte los cargos por el temor de sufrir una pena de prisión extremadamente alta. En un Estado de derecho, sin embargo, la pena solo es aceptable como un medio para la prevención tanto de los delitos como de los castigos arbitrarios, y por ello su distribución no puede ir más allá del merecimiento del autor, en atención a la gravedad del hecho y a su culpabilidad. Por tanto, cuando se amenaza con una pena que va más allá de lo que de manera razonable sea posible aceptar como una pena proporcional al delito cometido, con el objetivo de que el sujeto se allane a los cargos formulados, la pena se transforma en un mecanismo de tortura que en muy poco difiere de los ya denunciados por Beccaria (2011). En este caso la vulneración al principio de respeto a la dignidad humana no lo constituye propiamente la rebaja de penas por aceptación de cargos, ni los preacuerdos con la Fiscalía, sino que para ello se incremente la pena más allá de la pena proporcional (cualquiera que esta sea), pues en el fondo se amenaza al individuo con una pena injusta (que no merece) para obligarlo a aceptar su responsabilidad (sin excluir la posibilidad de que sea inocente) y así, luego de la rebaja de pena, terminar imponiendo -por lo menos es así en el caso colombianola pena que desde un comienzo hubiera correspondido. En este caso la amenaza en realidad opera como un nuevo tormento que permite la imposición de penas sin un juicio previo (Sotomayor Acosta, 2007).

\section{b. Las penas prohibidas: pena de muerte, destierro, confiscación y prisión perpetua}

La libertad de configuración del legislador colombiano en materia de penas ha sido limitada por el propio constituyente, que de manera expresa y absoluta consagró la prohibición de la pena de muerte, el destierro, la confiscación y la prisión perpetua.

1) Prohibición de la pena de muerte. La prohibición de esta pena no ha planteado 
problema de interpretación alguno, debido muy seguramente a la claridad de la norma constitucional (artículo 11). Tal limitación se encuentra reforzada en virtud de la incorporación al ordenamiento jurídico colombiano del "Segundo Protocolo facultativo del Pacto Internacional de Derechos Civiles y Políticos destinado a abolir la pena de muerte", adoptado por la Asamblea General de las Naciones Unidas el 15 de diciembre de 1989 y aprobado mediante la Ley 297 del 17 de julio de 1996. Al realizar el control constitucional previo y automático que rige en Colombia en materia de tratados internacionales, la Corte Constitucional resaltó:

\begin{abstract}
[...] la muerte es una pena que desconoce la condición de persona del sancionado y destruye la propia credibilidad del Estado, pues la condena solo se reconoce como ejercicio legítimo de la coacción estatal cuando se ejerce con el máximo grado de garantías individuales y no se desconoce la dignidad del delincuente. En efecto, los derechos humanos implican que existen medios -como la tortura o la pena de muerte- que nunca pueden ser utilizados para defender el ordenamiento jurídico, por cuanto su utilización viola precisamente aquellos valores que hacen digno de defensa el ordenamiento (Corte Constitucional, 1997a).
\end{abstract}

2) Prohibición de la pena de destierro. El artículo 34 de la Const. Pol. prohíbe también la pena de destierro, cuya última consagración positiva en el orde- namiento penal colombiano data del C. P. de 1890 (artículo 68). Esta pena ha sido definida por la Corte Constitucional como la "expulsión del territorio del Estado, de manera temporal o permanente, de una persona que ha cometido un delito" (Corte Constitucional, 2000a). Hasta la fecha esta prohibición solo ha planteado algunas dificultades en relación con los límites de la jurisdicción indígena, pues al resolver algunos casos en los que las autoridades indígenas tomaron la decisión de expulsar del respectivo resguardo a un infractor perteneciente a su comunidad, la Corte Constitucional había considerado que tales prácticas no encajaban en la prohibición constitucional del artículo 34, toda vez que "la pena de destierro solo se refiere a la expulsión del territorio del Estado y no a la exclusión de las comunidades indígenas que habitan un espacio de dicho territorio, pero que no exhiben el carácter de Naciones" (Corte Constitucional, 1997c). No obstante, al decidir una acción de tutela en 2015 la Corte Constitucional varió dicho criterio, al considerar frente al mismo problema que la expulsión de un miembro de una comunidad indígena del territorio del respectivo resguardo es un acto materialmente equivalente a la pena de destierro y por tanto se encuentra prohibido por el artículo 34 Const. Pol. Según la Corte Constitucional (2015e),

[...] aun cuando es cierto que la expulsión de un indígena solo tiene efectos en el territorio de 
su jurisdicción, es posible que ella adquiera la connotación y efectos de un verdadero destierro por comportar una exclusión definitiva del contexto que constituye el espacio vital de un individuo o de su familia, especialmente en aquellos casos en los que se trata de comunidades indígenas que conservan en mayor grado unos usos y costumbres propios. En estos eventos, la decisión sancionatoria bien podría estar comprendida dentro de lo que resulta realmente intolerable por atentar contra los bienes más preciados del ser humano.

3) Prohibición de la pena de confiscación. La pena de confiscación ha sido entendida por la jurisprudencia como el absoluto despojo de los bienes por un acto del Estado que se impone a título de pena, sin compensación alguna y sin que tales bienes tengan vinculación alguna directa con actividades ilícitas (Corte Constitucional, 2002c). Pese a que su prohibición también parece tener un carácter absoluto (artículo 34 Const. Pol.), podría plantear algunas dudas el hecho de que el mismo artículo posibilite que por sentencia judicial se declare la extinción de dominio "sobre los bienes adquiridos mediante enriquecimiento ilícito, en perjuicio del tesoro público o con grave deterioro de la moral social".

La jurisprudencia constitucional ha diferenciado la confiscación tanto del comiso (artículo 100 C. P.) como de la figura de la expropiación (artículo 58 Const. Pol.) y de la extinción de dominio (artículo 34 Const. Pol.). Res pecto del comiso, entiende la Corte Constitucional que no se trata de una confiscación por cuanto, si bien es una pena, recae de manera exclusiva sobre "los bienes, objetos o instrumentos con los cuales se cometió la infracción y todas aquellas cosas o valores que provengan de la ejecución del delito" (Corte Constitucional, 1993a). Tampoco se ha entendido que la extinción de dominio constituya una forma de confiscación, al considerarse una figura autónoma, que no supone de manera necesaria la realización previa de un delito (artículo 18, Ley 1708 de 2014), por lo que a diferencia del comiso no puede ser entendida como una pena; aún más, ni siquiera es propiamente una limitación del derecho de propiedad, como ocurre con la expropiación, pues lo que se discute y declara es "la inexistencia del derecho a la propiedad debido a la ilicitud de los medios a través de los cuales este fue en apariencia adquirido" (Corte Constitucional, 1997b; Corte Constitucional, 2011b).

Tal como ha sido regulada en el ordenamiento jurídico colombiano (Ley 1708 de 2014) es cierto que la extinción de dominio no constituye propiamente una pena. Ahora bien, desde una perspectiva constitucional habría que entender que lo prohibido por el artículo 34 Const. Pol. es que el Estado de manera coactiva despoje a una persona de sus bienes, sin indemnización (a diferencia de la expropiación) y sin que los mismos se encuentren vinculados a la realización de actividades ilícitas 
(a diferencia del comiso), independientemente de la denominación que se dé al acto como tal. Luego, para no configurar una forma camuflada de confiscación debe entenderse que la extinción de dominio presupone la vinculación de los bienes con el "enriquecimiento ilícito", el "perjuicio del tesoro público" o el "grave deterioro de la moral social" (artículo 34 Const. Pol.), lo que excluiría su aplicación respecto de bienes de origen y uso lícitos. Por este motivo resulta muy dudosa la constitucionalidad de las causales 9, 10 y 11 de la Ley 1078 de 2014, en las cuales se permite la extinción de dominio respecto de bienes de procedencia lícita, "mezclados material o jurídicamente con bienes de ilícita procedencia" (N. 9); "cuando la acción resulte improcedente por el reconocimiento de los derechos de un tercero de buena fe exenta de culpa" (N. $\left.{ }^{\circ} 10\right)$; $\mathrm{o}$, finalmente, "cuando no sea posible la localización, identificación o afectación material de estos" (N. $\left.{ }^{\circ} 11\right)$.

Es de resaltar que precisamente por el grado de incidencia que la acción de extinción de dominio puede acarrear en derechos fundamentales, la propia Corte Constitucional, en relevante decisión que supuso una variación del precedente jurisprudencial sobre el tema, declaró inconstitucional la falta de control judicial, por parte de un juez de garantías, de las medidas de intervención que realice la Fiscalía General de la Nación sobre los derechos fundamentales (i. e. allanamientos, interceptaciones de comunicaciones y búsquedas en bases de datos), en desarrollo del procedimiento de extinción de dominio (cfr., Corte Constitucional, 2015c).

4) Prohibición de la prisión perpetua. El artículo 34 Const. Pol. prohíbe también de manera expresa la pena de prisión perpetua, lo cual en principio no parecería plantear mayores dificultades interpretativas. Aunque no hay pronunciamientos puntuales de la Corte Constitucional sobre el tema, la prohibición de la prisión perpetua suele entenderse como consecuencia de la interdicción constitucional de las penas crueles, inhumanas y degradantes, incompatibles con el principio de respeto a la dignidad humana (Corte Constitucional, 1993e). Y es que, en efecto, un derecho penal centrado en la persona presupone el derecho del individuo a la reintegración o readaptación social, pues la realización del ser humano no se agota en el hecho de existir, sino que involucra también el ser social, y en este sentido el Estado no debería imponer penas que excluyan la posibilidad de readaptación social. La existencia de este derecho explica, por un lado, la proscripción de ciertas penas como la de muerte, el destierro y la prisión perpetua, que de antemano resultan incompatibles con el mismo y, por otro, ciertas restricciones al contenido de la ejecución de las penas privativas de la libertad, con el fin de garantizar que de alguna manera el sujeto siga en contacto con el mundo externo. De ahí, en consecuencia, la previsión constitucional de que las penas 
privativas de la libertad se orienten de manera esencial a la "reforma y la readaptación social" de los condenados, como lo establecen de manera expresa los artículos 10 numeral 3, del Pacto Internacional de Derechos Civiles y Políticos (Ley 74 de 1968), y 5 numeral 6 de la Convención Americana de Derechos Humanos (ley 16 de 1972), los cuales integran el bloque de constitucionalidad (artículo 93 Const. Pol.), y las normas rectoras del derecho penal colombiano (artículo 2 C. P.).

La doctrina suele entender que el derecho a la reinserción social incluye dos exigencias (Cid Moliné, 1998): por una parte, que la duración de la pena no implique en la práctica la negación de las posibilidades de readaptación; y, por otra, que durante la ejecución de la pena no se anule la relación del condenado con el mundo externo. Luego, no se trata entonces de que conforme al texto constitucional la pena encuentre su justificación en la finalidad resocializadora y mucho menos que el Estado pueda imponer un tratamiento tendente a rehabilitar o resocializar al sujeto, lo cual sería, sin duda, inconstitucional por lesionar la libertad moral del condenado (Ferrajoli, 1995). Lo inaceptable desde el punto de vista constitucional es más bien que se imponga una pena que por su duración o ejecución le impide al sujeto reintegrarse a la sociedad.

Esto significa que la pena de prisión no puede durar para siempre (que es lo que al fin de cuentas significa la expresión "perpetua"), es decir, que debe no solo tener prevista una duración máxima, sino una duración máxima que el sujeto pueda efectivamente cumplir y tener luego la oportunidad de reintegrarse a la sociedad. Lo primero conduce tanto a la prohibición de la prisión perpetua como de las penas de prisión que por su larga duración se tornan desde un comienzo incumplibles para todas las personas, pues en tales casos se está ante situaciones materialmente equivalentes: son penas que durarán para siempre. Cabe insistir, por tanto, en que la pena máxima de prisión prevista en la actualidad en los 60 años (artículo 31 C. P.), (solo para los casos de concurso de conductas punibles), obviamente no es compatible con la prohibición constitucional de la prisión perpetua, pues no existe ninguna expectativa real de que una persona sobreviva a un encierro carcelario de esta duración ${ }^{8}$.

8 Dado que, por una parte, según datos del Banco Mundial en Colombia la expectativa de vida para el período 2011-2015 se ha estimado en 74 años (cfr., http://datos.bancomundial.org/indicador/SP.DYN. LE00.IN, consultado el 24/03/2016) y, por otra, el C. P. solo es aplicable a las personas mayores de 18 años. A pesar de ello la Corte Constitucional (1993f), avaló la constitucionalidad de las penas de 60 años previstas en ese momento en la Ley 40 de 1994, con el absurdo argumento de que "lo perpetuo es lo intemporal, esto es, lo que no tiene límites ni medidas en el tiempo, lo infinito, de tal suerte que tiene un comienzo, pero no un fin. La norma en comento tiene un límite temporal preciso y determinado; por lo tanto, no puede decirse que ella es perpetua" (cursivas agregadas; el argumento es tomado de otra sentencia (Corte Constitucional, 1993c) la cual de todas maneras declaró inexequible, aun cuando por otros motivos, la totalidad de los artículos del Decreto 709 de 1993). Dicho argumento se cae de inmediato de su peso, pues según ello una pena máxima de cien o doscientos años no sería perpetua pues tiene un límite temporal "preciso y determinado". 
Aún más, como no se trata de que el sujeto salga simplemente a morir fuera de la cárcel sino de que se reintegre a la sociedad, la pena de prisión debe tener una duración razonable, de manera que la persona pueda no solo cumplirla sino también vivir de nuevo en sociedad; y si bien en este caso la fijación de dicho límite corresponde de manera exclusiva al legislador, su actividad se encuentra de todas maneras limitada por la prohibición constitucional de exceso punitivo (Corte Constitucional, 1993e; Corte Constitucional, 2002d), conforme a las exigencias de un trato humano y digno.

\section{c. La prohibición de la prisión por deudas}

La prohibición de la prisión por deudas (artículo 28 Const. Pol.) parece estar avalada por el principio de intervención mínima y más concretamente por el carácter fragmentario del derecho penal, según el cual el derecho penal solo debe utilizarse frente a las más graves afectaciones a los bienes jurídicos y siempre que no haya mecanismos menos drásticos e igualmente efectivos. El injusto penal presupone algo más que un ilícito extrapenal (Díez Ripollés, 1991), dado que se trata de utilizar precisamente el más grave y odioso de los mecanismos punitivos a cargo del Estado y, por tanto, acudir a la pena ante impago de una deuda se presume en todo caso desproporcionado.

Lo anterior plantea algunas dificultades de interpretación en el caso de impago de la pena de multa, dado que el artículo 40 C. P. permite su conversión en arresto progresivo. En diferentes oportunidades la Corte Constitucional se ha pronunciado sobre este punto en el sentido de entender que no se contraría la norma constitucional, puesto que "la multa se impone -y se convierte en arresto- no por el incumplimiento de obligaciones contractuales que es lo que prohíbe la norma superior, sino en razón del resarcimiento por la lesión que se haya inferido al orden social al no cumplirse con la pena principal impuesta -la multa-" (Corte Constitucional, 1996b). Se ha considerado, igualmente, que el "juicio de reprochabilidad de una específica conducta corre el riesgo de tornarse en pauta no obligatoria de conducta, si a la conducta desviada y a la elusión de su respectiva sanción no sigue consecuencia adversa alguna" (Corte Constitucional, 1994).

Entender que el artículo 28 constitucional, cuando se refiere a la proscripción de la privación de la libertad por "deudas" se refiere solo a deudas civiles o contractuales, es algo que resulta a todas luces discutible, pues una deuda no es cosa distinta a la obligación de pagar algo a otro; en este punto la Constitución colombiana, acorde con lo establecido en el numeral 7 de la Convención Americana de Derechos Humanos (Ley 16 de 1072), establece una prohibición mucho más amplia que la prevista en el artículo 11 del Pacto Internacional de Derechos Civiles y Políticos de la ONU (Ley 74 de 1968), según el cual "nadie será encarcelado por el solo hecho de no poder cumplir una obligación contractual". Lo que la Constitución y la Convención Americana prohíben es algo más que la prisión por un incumplimiento 
contractual: es la prisión por deudas, cualquiera sea el origen de la misma. Y es que, en efecto, cuando se impone una pena de multa surge para el condenado la obligación de pagar al Estado una suma de dinero, esto es, adquiere una deuda; solo que en este caso dicha deuda no tiene un origen contractual sino la imposición de una sanción. Y si bien es cierto que el Estado tiene derecho a asegurar la efectividad de sus sanciones, eso no significa que lo pueda hacer de cualquier manera; en el caso de la multa, además de su posible amortización por plazos o mediante trabajo (artículo 39 C. P.), existe siempre la posibilidad de que el Estado acuda al cobro de ejecución coactiva prevista en el artículo 41 C. P.

La constitucionalidad de la conversión de la pena de multa en arresto progresivo puede ser discutida, además, desde otros puntos de vista: en primer término, es contradictorio que en razón de la menor gravedad del hecho el legislador decida castigar la comisión de un delito con la pena de multa, pero luego esta pueda ser sustituida por la pena más drástica, que es la privativa de la libertad. Además, parece configurar un caso de infracción del principio de subsidiariedad interna, pues ya la propia ley penal prevé otros mecanismos menos drásticos (amortización mediante trabajo y ejecución coactiva) para el caso de impago de la multa. Y, finalmente, la falta de recursos económicos para pagar la multa no legitima una pena privativa de la libertad, pues sería directamente un derecho penal clasista por cuanto las personas de menor capacidad económica tendrían, por esa sola condición, mayores posibilidades de ser privados de la libertad, lo que implicaría un tratamiento desigual no justificado ${ }^{9}$, contrario al artículo 13 Const. Pol.

De igual manera, tampoco parece constitucionalmente admisible condicionar el acceso a ciertos derechos y beneficios frente a la privación de la libertad, al pago de la multa o a la reparación de los perjuicios, pues de nuevo aquí la única razón para que el sujeto permanezca privado de la libertad sería el no pago de la deuda (con mayor razón si se trata de la indemnización de perjuicios).

\section{d. La prohibición de penas y medidas de seguridad imprescriptibles}

El artículo 28 Const. Pol. prevé también como restricción al poder sancionador del Estado la prohibición de imprescriptibilidad, tanto de las penas como de las medidas de seguridad. Con la referencia a estas últimas se zanjó del todo el debate que en vigencia de la Constitución de 1886 (que solo aludía a la imprescriptibilidad de las penas) y del C. P. de 1980 ocupó a la doctrina y a la jurisprudencia de la época, en relación con la constitucionalidad o no de la duración indeterminada de las medidas de seguridad previstas para los sujetos declarados como inimputables ${ }^{10}$, asunto sobre el que en su momento se pronunció de forma negativa la Corte Constitucional,

Distinto sería que hubiese fraude por parte del condenado, pues en tal caso no se trataría ya del no pago por incapacidad económica sino de la elusión del mismo.

10 Un análisis de dicho debate, en Agudelo (1984) y más ampliamente en Sotomayor Acosta (1996). 
al considerar que unas medidas de seguridad indeterminadas serían imprescriptibles $^{11}$. Luego, hoy en día no existe duda alguna de que tanto las penas como las medidas de seguridad, inclusive cuando son aplicadas a sujetos declarados inimputables, se encuentran sometidas a la prohibición de imprescriptibilidad.

Esta misma interpretación ha llevado a la Corte Constitucional a entender que no puede haber tampoco sanciones indeterminadas o perpetuas en general, inclusive las de carácter disciplinario y de policía ${ }^{12}$.

Los problemas de interpretación de esta prohibición se centran hoy en dos puntos: el primero es el de si la prohibición constitucional se refiere solo a la imprescriptibilidad de las penas y medidas de seguridad (artículo 88 C. P.), o si la misma cubre también la de la acción penal (artículo 83 C. P.); el segundo se refiere al impacto que en dicha norma ha tenido la incorporación al ordenamiento jurídico colombiano de tratados internacionales que prevén la imprescriptibilidad de algunos delitos, como es el caso de aquellos de competencia de la Corte Penal Internacional (CPI).

La Corte Constitucional, aunque con matices relevantes, ha optado por entender que tal prohibición se refiere solo a la imprescriptibilidad de las sanciones, es

$1 \quad$ Al respecto se ha pronunciado la Corte Constitucional (1993b), siendo además recogido por el vigente C. P. de 2000, al fijarle límite máximo a la duración de las medidas de seguridad aplicables al inimputable (artículos 70, 71, 72 y 76 C. P.).

12 Véase, entre otras, Corte Constitucional (2000a, 2000b, 2001a, 2008). decir, no a las posibilidades de persecución del delito, por cuanto considera que el artículo 28 constitucional busca proteger la libertad personal frente a la actividad punitiva material del Estado, a efectos de lo cual condiciona los actos de las autoridades encargadas de hacer cumplir las decisiones a través de las cuales el Estado hace efectiva la privación de la libertad de alguien (Corte Constitucional, 2002b; Corte Constitucional, 2011c). Toda privación de la libertad presupone, salvo contadas excepciones (como la captura administrativa y la flagrancia), una decisión judicial previa, por lo que en opinión del alto tribunal: "mientras no exista una sentencia condenatoria, una medida que ordene una detención preventiva, o una captura, no se puede afirmar que hay una resolución estatal que constituya el título mediante el cual el Estado pueda afectar materialmente la libertad individual de una persona" (Corte Constitucional, 2002b). De aquí deduce la Corte que solo la imprescriptibilidad de la sanción (pena y medida de seguridad) se encuentra cubierta por la prohibición constitucional, por cuanto "la prescripción de la acción penal no puede concebirse como un mecanismo de protección frente a la libertad personal salvo que una autoridad judicial haya proferido una resolución que tenga la potencialidad de afectar materialmente la libertad personal de un individuo determinado" (Corte Constitucional, 2002b). En este último caso procede entonces una ponderación de competencia exclusiva del legislador que, en últimas, es a quien corresponde en principio dictar la regla sobre la prescripción de la acción penal (Corte Constitucional, 2002b). 
Pese a la finura y coherencia de esta argumentación, es discutible la premisa a partir de la cual se construye: que el artículo 28 se dirige a las autoridades encargadas de materializar la privación de libertad de una persona. En efecto, dicha norma parece dirigida también al legislador, por ejemplo, al momento de establecer los límites y controles de la captura, la prisión preventiva o la pena misma, pues de esa manera también se afecta el derecho fundamental a la libertad; cabe recordar que también en la fase de indagación de un delito, aun cuando todavía no exista una imputación contra una persona determinada, la autoridad realiza actos de investigación contra personas indiciadas, entre ellos, registros y allanamientos, retención de correspondencia, interceptación de comunicaciones (en general, artículos 213 a 245, Ley 906 de 2004); luego, desde el punto de vista constitucional resulta coherente entender la prohibición de imprescriptibilidad como un mecanismo orientado a garantizar la libertad personal en general y a evitar la instrumentalización del individuo, punto de vista desde el cual el problema de la prescripción de la acción penal resulta también relevante, pues, sin duda, ante una indagación indefinida existe siempre la posibilidad real de que a efectos de evitar el menoscabo del fin preventivo en virtud de la falta de prontitud y certeza de la pena (Beccaria, 2011), dicha amenaza tenga que concretarse en algún momento en alguien, con el riesgo de que la persona simplemente sea instrumentalizada como ejemplo de retribución del sistema penal (Nanzer, 2009), al tiempo que, además, se desconocen también las exigencias del debido proceso, en particular el derecho a un proceso sin dilaciones injustificadas (Pastor, 2004), y la seguridad jurídica.

En definitiva, lo correcto desde el punto de vista de la exigencia constitucional de respeto a la dignidad humana parecería indicar que la prohibición de imprescriptibilidad se refiere tanto al ejercicio de la acción penal como a las sanciones propiamente tales, lo cual obliga al legislador a establecer entonces un plazo razonable y proporcional de prescripción en ambos casos (Corte Constitucional, 1995). Solo cabe admitir como tratamiento diferencial, el derivado de la incorporación al derecho interno de algunos tratados internacionales sobre derechos humanos, en particular el Tratado de Roma (Ley 742 de 2002), la Convención interamericana sobre desaparición forzada de personas (Ley 707 de 2001) y la Convención internacional para la protección de todas las personas contra las desapariciones forzadas (Ley 1418 de 2010), entre otros. La incorporación de estos tratados, sin dudas, ha influenciado de manera notable la jurisprudencia constitucional, de lo cual ha salido como resultado después de superado el control constitucional previo, una compleja regulación de las posibilidades de prescripción o no de los delitos de competencia de la CPI y muy en particular del delito de desaparición forzada, que podría resumirse de la siguiente manera:

a) De conformidad con la sentencia C-578 de 2002, el artículo 29 del Estatuto de Roma, según el cual "Los crímenes de competencia de la Corte no pres- 
cribirán", constituye un tratamiento diferente al interno (artículo 28 Const. Pol.), lo cual, de conformidad con el Acto Legislativo 02 de 2001, significa que se está en presencia de una regulación aplicable exclusivamente en el ámbito de competencia de la CPI, sin que modifique o cambie la legislación interna. Por tanto:

"Tal tratamiento especial solo será aplicable por la Corte Penal Internacional cuando ejerza su competencia complementaria para investigar y juzgar cualquiera de los crímenes previstos en el Estatuto, así la acción penal o la sanción penal para los mismos haya prescrito según las normas jurídicas nacionales" (Corte Constitucional, 2002a).

b) En el caso exclusivo del delito de desaparición forzada, en razón de lo previsto en la Convención interamericana sobre esta materia, el tratamiento es diferente, pues frente a la pena rige la misma prohibición constitucional de imprescriptibilidad, pero en lo que tiene que ver con la acción, la misma puede ser tanto prescriptible como imprescriptible ${ }^{13}$ : sería prescriptible desde el momento en que la investigación se dirige en concreto contra sujetos individualizados, ya que la tensión entre los derechos del procesado y los de las víctimas y de la sociedad en general, se resuelve imponiendo un término de investigación y juzgamiento, en razón de la afectación que representa

13 Corte Constitucional, sentencia C-620 de 2011, citada. la existencia de un proceso contra los sujetos implicados. Pero la acción es imprescriptible cuando no se haya vinculado al proceso a persona alguna, pues en tal evento la ponderación se resuelve en favor de los intereses que avalan el castigo de este delito (Corte Constitucional, 2011c).

\section{CONCLUSIONES}

A pesar de las dificultades existentes en la determinación del contenido de la dignidad humana como norma constitucional, la jurisprudencia constitucional permite derivar un contenido mínimo que permita limitar la potestad del Estado de castigar. Esta construcción conceptual debe abandonar la intención de ciertos ámbitos de la doctrina penal que pretenden derivar de la dignidad humana todos los límites al poder punitivo, convirtiéndola en una herramienta inútil por su volatilidad. Por el contrario, se propone una versión que, aunque discursivamente menos poderosa, logra determinar el contenido del derecho constitucional a la dignidad humana en materia penal, buscando que los mismos tengan una aplicación práctica más allá de la retórica liberal/ilustrada que ha enmarcado a las garantías penales.

El presente artículo muestra cómo de la dignidad humana pueden derivarse diversos contenidos, vinculados con otras normas constitucionales. En primer lugar, está la prohibición general de la tortura, los tratos y penas crueles, inhumanas y degradantes. En segundo lugar, se encuentra la prohibición explícita de ciertas formas de castigo, concretamente, de la 
pena de muerte, destierro, confiscación y prisión perpetua. En tercer lugar, se encuentra la prohibición de la prisión por deudas; y, finalmente, se encuentra la prohibición de penas y medidas de seguridad imprescriptibles.

Estos cuatro límites al poder punitivo derivados de la Constitución tienen una aplicación directa a través de las herramientas de control constitucional concentrado y difuso establecidas en el ordenamiento colombiano; de igual manera sirven como herramientas de interpretación en las decisiones de los jueces, especialmente de aquellos encargados de vigilar la ejecución de la pena.

Si bien la propuesta de este artículo puede representar una limitación de otros discursos sobre la dignidad humana, la precisión agregada a través de estos cuatro contenidos implica una mayor capacidad garantista para un derecho cuya caracterización ha sido bastante elusiva para la jurisprudencia y la doctrina. Sin embargo, el trabajo realizado reconoce, además, las limitaciones propias de la definición de un derecho constitucional ligado a cierta codificación positiva, con lo cual advierte que el trabajo de construcción de la dignidad humana es menos un asunto de una axiología universal prepositiva, y más un problema de política criminal ligada al texto constitucional y a las interpretaciones jurisprudenciales.

\section{REFERENCIAS}

Agudelo Betancur, N. (1984). Inimputabilidad y responsabilidad penal. Bogotá: Temis.
Arango, R. (2005). El concepto de derechos sociales fundamentales. Bogotá: Legis.

Beccaria, C. (2001). De los delitos y de las penas (edición bilingüe a cargo de P. Andrés Ibáñez). Madrid: Trotta.

Berlin, I. (2003). Cuatro ensayos sobre la libertad. Madrid: Alianza.

Bernal Pulido, C. (2005). El derecho de los derechos. Bogotá: Universidad Externado de Colombia.

Borja Jiménez, E. (1992). Algunas reflexiones a raíz de la nueva formulación del principio de culpabilidad en el anteproyecto de código penal de 1992. Nuevo Foro Penal, (57), 349-368.

CEPEDA, M. J. (1992). Los derechos fundamentales en la Constitución de 1991. Bogotá: Temis.

Cid Moliné, J. (1998). Derecho a la reinserción social (Consideraciones a propósito de la reciente jurisprudencia constitucional en materia de permisos). Jueces para la Democracia, (32), 36-49.

Corte Constitucional (1993a). Sentencia C-076. M. P. Alejandro Martínez Caballero.

Corte Constitucional (1993b). Sentencia C-176. M. P. Alejandro Martínez Caballero.

Corte Constitucional (1993c). Sentencia C-275. M. P. Antonio Barrera Carbonell.

Corte Constitucional (1993d). Sentencia C-530. M. P. Alejandro Martínez Caballero.

Corte Constitucional (1993e). Sentencia C-591. M. P. Eduardo Cifuentes Muñoz.

Corte Constitucional (1993f). Sentencia C-565. M. P. Hernando Herrera Vergara.

Corte Constitucional (1994). Sentencia C-041. M. P. Eduardo Cifuentes Muñoz.

Corte Constitucional (1995). Sentencia C-345. M. P. Eduardo Cifuentes Muñoz.

Corte Constitucional (1996a). Sentencia C-022. M. P. Carlos Gaviria Díaz.

Corte Constitucional (1996b). Sentencia C-628. M. P. Hernando Herrera Vergara. 
Corte Constitucional (1997a). Sentencia C-144. M.

P. Alejandro Martínez Caballero.

Corte Constitucional (1997b). Sentencia C-374. M.

P. José Gregorio Hernández Galindo.

Corte Constitucional (1997c). Sentencia T-523. M.

P. Carlos Gaviria Díaz.

Corte Constitucional (1998). Sentencia T-153. M.

P. Eduardo Cifuentes Muñoz.

Corte Constitucional (1999). Sentencia C-079. M.

P. Martha Victoria Sáchica Méndez.

Corte Constitucional (2000a). Sentencia C-110.

M. P. Antonio Barrera Carbonell.

Corte Constitucional (2000b). Sentencia C-1444.

M. P. Alfredo Beltrán Sierra.

Corte Constitucional (2001a). Sentencia C-046.

M. P. Álvaro Tafur Galvis.

Corte Constitucional (2001b). Sentencia C-093.

M. P. Alejandro Martínez Caballero.

Corte Constitucional (2002a). Sentencia C-578. M.

P. Manuel José Cepeda Espinosa.

Corte Constitucional (2002b). Sentencia C-580.

M. P. Rodrigo Escobar Gil

Corte Constitucional (2002c). Sentencia C-764.

M. P. Jaime Córdoba Triviño.

Corte Constitucional (2002d). Sentencia C-939.

M. P. Eduardo Montealegre Lynett.

Corte Constitucional (2002e). Sentencia T-881. M.

P. Eduardo Montealegre Lynett.

Corte Constitucional (2003a). Sentencia C-205.

M. P. Clara Inés Vargas Hernández.

Corte Constitucional (2003b). Sentencia C-804.

M. P. Jaime Araújo Rentería.

Corte Constitucional (2008). Sentencia C-290. M.

P. Jaime Córdoba Triviño.

Corte Constitucional (2011a). Sentencia C-399. M.

P. Humberto Antonio Sierra Porto.

Corte Constitucional (2011b). Sentencia C-459. M.

P. Jorge Ignacio Pretelt Chaljub.
Corte Constitucional (2011c). Sentencia C-620. M. P. Juan Carlos Henao Pérez.

Corte Constitucional (2013). Sentencia T-388. M. P. María Victoria Calle Correa.

Corte Constitucional (2015a). Sentencia C-143. M. P. Luis Ernesto Vargas Silva.

Corte Constitucional (2015b). Sentencia T-762. M. P. Gloria Stella Ortiz Delgado.

Corte Constitucional (2015c). Sentencia C-516. M. P. Alberto Rojas Ríos.

Corte Constitucional (2015d). Sentencia T-099. M. P. Gloria Stella Ortiz Delgado.

Corte Constitucional (2015e). Sentencia T-300. M. P. Luis Guillermo Guerrero Pérez

Díez Ripollés, J. L. (1991). La categoría de la antijuridicidad en derecho penal. Anuario de Derecho Penal y Ciencias Penales, (3), 715-790.

Fernández Carrasquilla, J. (2011). Derecho penal, parte general. Principios y categorías dogmáticas. Bogotá: Ibáñez.

Ferrajoli, L. (1995). Derecho y Razón. Teoría del Garantismo Penal (trad. P. Andrés Ibáñez y otros) Madrid: Trotta.

Ferrajoli, Luigi (2008). Sobre los derechos fundamentales. En L. Ferrajoli (Ed.), Democracia y garantismo (pp. 42-59). Madrid: Trotta.

Ferrajoli, L. (2011a). Principia Iuris. Teoría del derecho y de la democracia. 1. Teoría del derecho. Madrid: Trotta.

Ferrajoli, L. (2011b). Principia Iuris. Teoría del derecho y de la democracia. 2. Teoría de la democracia. Madrid: Trotta.

Gallego García, G. M. (2005). Sobre el concepto y fundamento de la dignidad humana. En F. Velásquez (Ed.), Derecho penal liberal y dignidad humana, Libro Homenaje al Dr. Hernando Londoño Jiménez (pp. 245-272). Bogotá: Temis.

Lopera Mesa, G. P. (2006). Principio de proporcionalidad y ley penal. Madrid: Centro de Estudios Constitucionales. 
Luzón Peña, D.-M. (2012). Lecciones de derecho penal, parte general. Valencia: Tirant lo Blanch.

Mir Puig, S. (2008). Derecho penal, parte general. $8^{\text {a }}$ edición. Barcelona: Reppertor.

Nanzer, A. (2009). La satisfacción de la víctima y el derecho al castigo. En D. R. Pastor (Dir.) y N. Guzmán (Coord.), El sistema penal en las sentencias recientes de los órganos interamericanos de protección de los derechos humanos (pp. 353 376). Buenos Aires: Editorial Ad-Hoc.

Nino, C. S. (1980). Los límites de la responsabilidad penal. Una teoría liberal del delito. Buenos Aires: Astrea.

Nino, C. S. (1989). Ética y derechos humanos. Un ensayo de fundamentación. Barcelona: Ariel.

Pastor, D. (2004). Acerca del derecho fundamental a un plazo razonable de duración del proceso penal. Jueces para la Democracia, (49), 51-65.

Prieto Sanchís, L. (2011). Garantismo y derecho penal. Madrid: Iustel.

Quinche Ramírez, M. F. (2012). Derecho constitucional colombiano: de la carta de 1991 y sus reformas. Bogotá: Temis.

Rodríguez Garavito, C. A. (2007). Derecho a la igualdad. En H. López y R. Posada, Manual de Constitución y democracia. Volumen 1. De los derechos (pp. 189-204). Bogotá: Universidad de los Andes.

Roxin, C. (2007). ¿Es la protección de bienes jurídicos una finalidad del Derecho penal?
(Traducción de I. Ortiz de Urbina Gimeno). En R. Hefendehl (Ed.), La teoría del bien jurídico. ¿Fundamento de legitimación o juego de abalorios dogmáticos? (pp 443-458). Madrid: Marcial Pons.

Sotomayor Acosta, J. O. y Tamayo Arboleda, F. L. (2017). Dignidad humana y Derecho penal: una difícil convergencia. Aproximación al contenido constitucional de la norma rectora del artículo 1 del C.P. colombiano. Revista de Derecho, (48), 21-53.

Sotomayor Acosta, J. O. (1996). Inimputabilidad y sistema penal. Bogotá: Temis.

Sotomayor Acosta, J. O. (1999). Garantismo y derecho penal en Colombia. Jueces para la Democracia, (35), 92-98.

Sotomayor Acosta, J. O. (2007). Las recientes reformas penales en Colombia: un ejemplo de irracionalidad legislativa. Nuevo Foro Penal, (71), 3-66.

Velásquez V., F. (2009). Derecho penal parte general, $4^{a}$ edición. Bogotá: Comlibros.

Von Hirsch, A. (2007). El concepto del bien jurídico y el 'principio del daño'. En $R$. Hefendehl (Ed.), La teoría del bien jurídico. ¿Fundamento de legitimación o juego de abalorios dogmáticos? (pp. 33-90). Madrid: Marcial Pons.

Zaffaroni, E. R.; Alagia, A. y Slokar, A. (2002). Derecho penal parte general. Buenos Aires: Ediar. 